Proceedings of SALT 27: 302-322, 2017

\title{
Rhetorical questions: Severing questioning from asking*
}

\author{
María Biezma \\ University of Konstanz
}

\author{
Kyle Rawlins \\ Johns Hopkins University
}

\begin{abstract}
Rhetorical questions (RhQs) are puzzling for theoretical accounts of questions: while they have an interrogative form, they seem to provide the same information as a parallel assertion. We propose that solving this puzzle requires a deeper understanding of the dynamics of interrogative utterances, and in particular we argue for a dynamics parallel to what has recently been proposed for assertions and imperatives: uttering an interrogative is a proposal to update the context, in this case the QUD, and its acceptance leads to the final inquisitive update. We argue that RhQs are interrogatives triggering the presupposition that the context entails the answer, so if accepted as a QUD, they would be immediately answered. This, in combination with the dynamics we develop, allows us to explain both the similarities with assertions as well as the differences in their discourse function.
\end{abstract}

Keywords: questions, rhetorical questions, dynamics, update semantics, speech acts.

\section{What are rhetorical questions?}

The notion of rhetorical question (RhQ) has been slippery. In this paper, following Caponigro \& Sprouse 2007 (henceforth C\&S), we consider RhQs to be interrogative utterances that fulfill the following key hallmarks (where the first two are old observations, ${ }^{1}$ and the third is from $\mathrm{C} \& \mathrm{~S}$ ):
a. RhQs don't expect an answer.
b. RhQs have the feel of an assertion.
c. RhQs can optionally be answered.

\footnotetext{
* We are very grateful to Ana Arregui, Justin Bledin, Donka Farkas, and members of the DFG funded research unit Questions at the Interfaces and participants at a $\mathrm{PhD}$ seminar on questions taught at the University of Konstanz in SoSe 2017, especially Bettina Braun, Nicole Dehé, Sophie Egger, Felicitas Enders, Clara Huttenlauch, Farhat Jabeen, Angela James, Marianne Kusterer, Erlinde Meertens, Jana Neitsch, Maribel Romero, Yvonne Viesel, Ramona Wallner, Daniela Wochner and Mark-Matthias Zymla. This research was partially supported by DFG research unit FOR2111, Questions At The Interfaces for Biezma, and NSF INSPIRE BCS-1344269 for Rawlins. Authors are alphabetical.

1 See, among others, Sadock 1971, 1974; Ladusaw 1979; Progovac 1993; Han \& Siegel 1996; Gutiérrez Rexach 1997; Han 2002; van Rooy 2003; Rohde 2006; Reese 2007.
} 
Rhetorical questions: Severing questioning from asking

These hallmarks allow us to classify as RhQs the examples like those in (2):

a. Am I a nerd or am I a nerd?

(COCA)

b. PhD student whining a lot about the work she has to do:

Prof: Are you doing a PhD or vacationing in Konstanz?

c. You should stop saying that Luca didn't like the party last night. After all, who was the only one that was still dancing at $3 \mathrm{am}$ ?

d. At the entrance of a golf resort on a Saturday morning, club in hand:

Golfer: Can you possibly imagine a better way to spend a Saturday?

e. B does something very stupid:

A: Are you an idiot?

The interrogatives in (2) include alternative questions in which there is only one live alternative ( $2 \mathrm{a}$ and $2 \mathrm{~b}$ ) as well as interrogatives in which the overall interpretation (and the three hallmarks above) are obtained as result of the combination of linguistic cues and the context of utterance $(2 \mathrm{c}-\mathrm{d}) .^{2}$

In this paper we provide a characterization of RhQs meeting these three hallmarks as interrogatives that signal the speaker's attitude towards the answer as well as signaling that $\mathrm{s} / \mathrm{he}$ is assuming this attitude to be mutually accepted by all participants. This proposal is an extension of Caponigro \& Sprouse's (2007) common ground hypothesis: that a rhetorical question is one where the answer is already common ground. In this way, RhQs are in the same family as other questions that signal some agents' attitudes towards the answer, either the speaker's (e.g. high-negation questions, or reversed-polarity tag-questions) or the addressee's (e.g. same-polarity tag-questions). We suggest that RhQs, like those other interrogatives, do have (varied) conventional marking conveying an attitude towards the answer, but don't just serve to make a private attitude public. Rather, RhQs signal the speaker's assumption that the attitude is (or should be) mutually accepted by all participants. That is, RhQs are interrogatives with linguistic cues that trigger the presupposition that all participants are (or can be) privileged to the answer.

Before proceeding, notice that RhQs are distinct from assertions not just in form, as shown by the fact that they do not behave the same way in response patterns for agreement and disagreement:

2 This characterization leaves out examples in monologues like (i), uttered in a semantics talk:

(i) Presenter: [...] So, we have seen all the machinery we have at our disposal. Can we find an answer to our initial problem? Well, let's see...

In (i) the speaker doesn't expect the audience to respond. In fact, s/he may assume that the audience is in no position to provide an answer. The interrogative in (i) here is perhaps closer to a self-addressed question, though we leave open whether it is rhetorical in some broader sense. 
(3) Professor to the $\mathrm{PhD}$ student complaining about the amount of work:

$\mathrm{P}$ : Are you doing your $\mathrm{PhD}$ or vacationing in Konstanz?

S: You are right. / \#That's not true!

(4) John has just poured a gallon of iced-water over Tim's head for fun:

T: Are you an idiot?

$\mathbf{J}^{\prime}:\{$ You are right / \#That's true $\}$, I shouldn't have done that.

An account of RhQs also has to explain the differences and the similarities in these response patterns.

This characterization of RhQs leaves open an obvious question: if the speaker signals that the answer to the question is obvious/entailed in the context of utterance and hence already accepted by all participants, why would they utter an interrogative in the first place? Interrogatives, after all, are canonically used to signal ignorance and request information (Hintikka 1962; Searle 1969), whereas RhQs signal that all participants are privileged to a particular information. This is what we will term the Interrogative Form Puzzle (IFP). Understanding this puzzle requires us to understand the difference between uttering the interrogative, asking, and questioning, i.e. partitioning the context set in the future discursively-possible options (in a Stalnakerian sense). Explaining this difference, and other phenomena in RhQs, leads us to propose a dynamics for questions that severs the two. ${ }^{3}$ The core of our analysis is that, following Farkas \& Bruce 2010 on assertions and Starr 2016 on imperatives, asking a question proposes to update the context with that question, and accepting a proposed question leads to that update happening. In the case of rhetorical questions, in context the questioning part of the update is trivial but the proposal part isn't.

One main observation in response to the IFP is that rhetorical questions such as the ones we have already shown, as well as many standard examples in the literature such as C\&S's (5), are often used to extract a commitment to the rhetorical point from another speaker.

(5) You should stop saying that Luca didn't like the party last night. After all, who was the only one that was still dancing at $3 \mathrm{am}$ ?

That is, if the hearer goes along with a rhetorical question like (5), they too are committed to accepting that Luca was still dancing at 3am (and therefore that they are wrong about their larger point). On the severed view of rhetorical question, by accepting a rhetorical question, a speaker inevitably commits themselves to the answer that the questioner has signaled to exist, indicating that they have inferred

3 See Ginzburg \& Sag 2001; Ginzburg 2012 for a previous approach that made a distinction between these two, for very different purposes. 
the intended answer as well. In order to avoid this commitment, they will typically need to reject some presuppositions of the question at the proposal stage in order to reject the question itself.

The paper is organized as follows. In $\$ 2$ we discuss Caponigro \& Sprouse's (2007) common ground proposal for RhQs, introducing some limitations of the account. In $\S 3$ we further develop one point introduced when discussing these limitations - that the rhetorical nature of rhetorical questions is signaled in some way; we suggest that generally the signals are triggers for presuppositions. In $\S 4$ we develop a formal framework that implements the key proposal about asking vs. questioning, and provides a precise template for what this sort of signal contributes. We focus on two case studies where the signal contributes in the compositional semantics rhetorical alternative questions, and the German particle 'schon'.

\section{A first approximation to RhQs}

On Caponigro \& Sprouse's view, a rhetorical question is a regular question whose answer is known to both the speaker and the addressee - questions in which the answer is (already) part of the (Stalnakerian) Common Ground. ${ }^{4}$ From this, they argue, hallmarks (1a) and (1b) follow: an answer is not expected because it is already inferrable, and the question has the feel of an assertion because the asker publicly commits (in some sense) to a single proposition that is already in the common ground. We take this idea as our starting point, and refer to Caponigro and Sprouse's empirical generalization as the Common Ground Generalization. ${ }^{5}$

4 Caponigro \& Sprouse's (2007) formal account of rhetorical questions makes use of the Groenendijk \& Stokhof 1984 theory of questions, in which the denotation of an interrogative in a world of evaluation $w$ is the proposition that constitutes its complete true answer:

(i) An interrogative $\mathrm{Q}$ is a rhetorical question iff $\llbracket \mathbf{Q} \rrbracket^{w} \in \mathrm{CG}_{\mathrm{S}-\mathrm{A}}$ where $\mathrm{CG}_{\mathrm{S}-\mathrm{A}}=\{p: p$ is mutually believed by the Speaker and the Addressee $\}$

5 See Caponigro \& Sprouse 2007 for comparison to analyses that propose that (a) rhetorical questions are negative statements (Sadock 1971, 1974; Progovac 1993; Han \& Siegel 1996; Han 2002), (b) interrogatives with no answers (Ladusaw 1979; Gutiérrez Rexach 1997), or (c) plain ordinary questions imposing restrictions on what kind of answer they allow (van Rooy 2003); Caponigro and Sprouse argue that none of these analyses make the right predictions in general. For example, analyses under (a) cannot account for rhetorical questions such as Has the educational system been so watered down that anybody who's above average is now gifted? (Rohde 2006), which implies the truth of the content proposition. For (b), Caponigro and Sprouse point out that rhetorical questions can be answered; the following dialogue illustrates this:

(i) Speaker: You should stop saying that Luca didn't like the party last night. After all, who was the only one that was still dancing at $3 \mathrm{am}$ ?

Addressee or Speaker: Luca.

Finally, proposals like (c) predict that RhQs should impose a normal requirement to answer the 
While we follow $\mathrm{C} \& \mathrm{~S}$ in taking the common ground generalization to describe a necessary condition for rhetorical readings, in our view it is not sufficient. We argue that in order to be interpreted as RhQs, interrogative utterances must conventionally indicate the speaker's attitude. To support this claim we will first argue that C\&S's proposal overgeneralizes. We offer two kind of scenarios illustrating overgeneralization: (i) scenarios where the common ground generalization (in some form) holds and a question is felicitous as information-seeking without the two first hallmarks above, and (ii) scenarios where the common ground generalization holds but a question is infelicitous.

Given the common ground generalization, a prosecutor asking questions in court to a witness s/he has coached would be in fact uttering a series of rhetorical questions, but that is not how those questions are perceived (the addressee is expected to answer, and the prosecutor at least puts up the fiction of not committing to the known answer). ${ }^{6}$ Similarly, the A+ student writing down a test does not take the questions asked as a series of rhetorical questions, even though (in the ideal situation) $\mathrm{s} / \mathrm{he}$ takes it for granted that the questioner knows the answers and, in this scenario, the teacher also believes that $\mathrm{s} /$ he knows the answers. These examples demonstrate that the common ground generalization is not sufficient, and can be overridden.

In some cases scenarios that meet the common ground generalization are simply infelicitous. Underlining the two hallmarks of rhetorical questions in (1a) and (1b) is a rather basic fact: RhQs are felicitous despite the fact that they convey information instead of requesting it. This also predicts that RhQs are infelicitous when an assertion would be infelicitous and for (in principle) the same reasons, for example if the answer has been explicitly stated in prior discourse (it can be taken to be common ground). A question whose answer has been just given should be understood as a RhQ and be infelicitous when it is perceived as redundant: one can assert content that is (reasonably) taken to be CG to remind participants of it, but it is infelicitous if participants can take that content to be already prominent. This holds regardless of intonation: there is a characteristic (though hard to pin down) rhetorical prosody that in this case most naturally sounds sarcastic, with (perhaps among other features) exaggerated pitch contours and shifted focus to 'Konstanz',

question on the addressee, and that the answer cannot be provided by the questioner. However, even though RhQs can be answered no answer is ordinarily expected, and as seen above, the answer can be provided by either speaker or addressee.

6 One could argue that in this situations the common ground should be extended to all attendants to the court-session, i.e. the common ground is not just the common ground of the prosecutor and the witness, but also that of the jury and the audience attending the session. However, we could modify the scenario so everybody is in the know. In a scenario in which the star witness from the prosecution already told what he saw to the media and everybody in the room is aware of the story, the prosecutor's questions are still not perceived as rhetorical questions. 
Rhetorical questions: Severing questioning from asking

although we do not determine the exact pattern here. ${ }^{7}$

(6) A: Oh!, look at the map! Konstanz is in Germany, not in Switzerland!

$\mathrm{B}_{1}$ : \#What country is Konstanz in? ('neutral' interrogative prosody)

$\mathrm{B}_{2}$ : \#What country is Konstanz in? (RhQ prosody)

$\mathrm{B}_{3}$ : \#Konstanz is in Germany.

In (6), understanding that B heard and accepted A's statement (i.e. the answer can be taken to be Common Ground), $\mathrm{B}_{1}$ 's utterance should be understood as a RhQ on the common ground proposal. However, it is intuitively interpreted as an information-seeking question, and therefore feels odd in a context where A has just provided an answer. One can try to force a rhetorical reading with the various prosodic patterns discussed in the literature as in $\mathrm{B}_{2}$, but this still does not render the question felicitous in this context: intuitively, it feels redundant, as if there is no need to ask a rhetorical question. Similarly, a regular repetitive assertion in this context is also inappropriate. An account of rhetorical questions should derive all three of these facts, though we suggest that it is $\mathrm{B}_{2}$ and $\mathrm{B}_{3}$ that group together in terms of explanation: the account of rhetorical questions should lead to a similar account of the redundancy of these two types of move. $\mathrm{B}_{1}$ and $\mathrm{B}_{2}$ also differ in other sorts of contexts: $\mathrm{B}_{1}$ can be appropriate if the speaker simply didn't hear their interlocutor, whereas $B_{2}$ can't.

What transpires from the previous discussion is that in order to interpret an interrogative utterance as a RhQ, being able to infer common ground status of the answer is not enough: the utterance needs to include a conventional marking of a certain kind of speaker attitude - that the question they are asking is non-inquisitive in context. We will not attempt to give a general account of the (quite varied) means of encoding this, focusing instead on particular cases. We elaborate on several cases in §3: examples where there is a direct presupposition that forces rhetoricity, and cases where rhetoricity is derived in combination with contextual inferences. Our desiderata includes then providing an account of RhQs that makes the right predictions about these cases. This discourse model has to (i) explain why RhQs "feel" like assertions but still behave differently and (ii) why they have the

7 Much work remains to be done on understanding the interpretation of prosodic cues in rhetorical questions, which are quite varied, that this paper will not address. See Banuazizi \& Creswell 1999; Bartels 1999; Heeren, Bibyk, Gunlogson \& Tanenhaus 2015 for work on English or e.g. Wochner, Schlegel, Braun \& Dehé 2015, Neitsch, Kusterer, Dehé \& Braun 2017 for ongoing work on the investigation of the prosodic properties of rhetorical questions and their differences with plain information seeking questions in German. The prosody of rhetorical questions has also been related to prosody in other domains such as the prosody in exclamatives; see Sag \& Liberman 1975 and subsequent literature after it, as well as Cutler 1977 for discussion regarding the importance of the contextual situation on the interpretation of intonation. 
appearance of a question (syntactically they are interrogative clauses). At the end, we should also be able to explain the IFP: why speakers decide to utter a RhQ instead of its declarative counterpart.

\section{Signaling to be a RhQ}

Both in the court-room/exam scenarios and in (6), a single answering proposition is identifiable from the common ground. However, in none of these scenarios would it be felicitous for the questioner to form an assertion from that proposition (for different reasons). That is, because of the cultural conventions surrounding a courtroom, it would be completely inappropriate for an attorney to make assertions in place of the witness that $\mathrm{s} / \mathrm{he}$ is interrogating, and similarly for the exam situation. In the case of the Konstanz example, it would be infelicitous to repeat back A's claim about the location of Konstanz, as opposed to accepting the assertion or asking for more information. In sum, what is missing from Caponigro \& Sprouse characterization is that a question can only act to rhetorically convey information if the corresponding assertion would be felicitous in the first case. An account of RhQs should capture this fact. Our proposal is that, dynamically, the update performed by accepting a RhQ and a parallel assertion should have the same effect. In what follows we further support this claim which we formalize in $\$ 4$.

This assertability condition amounts to the claim that questions have a rhetorical reading only if the speaker conveys in the utterance of the interrogative itself that the answer is inferrable to or already believed by the addressee, and non-controversial relative to the common ground (just as any presupposition). It also requires that no public commitment (see Gunlogson 2001) has been already made by the addressee regarding $p$ (just like asserting $p$ requires the speaker has not committed to $p$ in the immediate discourse). Minimally, that the context entails the answer is a speaker presupposition (in the Stalnakerian sense; Stalnaker 1970, 2014). Following Stalnaker 2002, we take it that the act of signalling a pragmatic presupposition is interpreted iteratively: a participant in a context presupposes that $\varphi$ if she accepts that it is commonly accepted by participants that $\varphi$, all accept that all accept that $\varphi$, all accept that all accept that all accept it, etc. To say that rhetorical questions presuppose that the answer is entailed in the context of utterance (and hence available to all participants) is to say that they signal that the answer is already part of the common ground (Stalnaker 2014).

How is the presupposition that the answer is already part of the common ground triggered/signaled in the utterance of an interrogative? There are two strategies: (i) indicate with the conventional meaning of the utterance that the answer is (or should be) known to the speaker and addressee, and (ii) the conventional meaning together with the context of utterance makes it clear that the speaker takes it that 
Rhetorical questions: Severing questioning from asking

the context of utterance entails the answer, as in (15) where rhetoricity is the result of the interrogative together with its prosodic features in the context of utterance. In the case of (i), the question may even indicate what the answer is, as in doubled alternative questions. We briefly discuss each of these cases in more detail.

\subsection{The signal alone}

Rather than try to be comprehensive about all the ways in which a rhetorical question could be marked, we focus on two case studies. First, we discuss rhetorical alternative questions, and then we look briefly at the German particle 'schon'.

Rhetorical alternative questions Alternative questions (ALTQs; see Biezma \& Rawlins 2015 for an overview) in English are disjunctive questions with a final falling contour. We suggest that ALTQs can be understood as rhetorical when they present only one live alternative relative to the context of utterance, and that this is signaled by the conventional presuppositions of an ALTQ - that the alternatives presented by the question exhaust the contextual possibilities. This is what we have already seen with the ordinary alternative question in (3). In the PhD example in (3), the evidence suggests that the first alternative is true and common ground, though not something anyone has made a public commitment to in the discourse. Moreover, since it is a question, the discourse-appropriate response must choose one of the alternatives - given this fact, the professor expects the student to choose the first. The particular complaints about work, though, would (it is implied) be diminished only by the vacation alternative, and so the professor implies that this alternative is to be set aside.

A second use of a rhetorical alternative question is the doubled alternative question, introduced earlier in (2a). Here we provide other attested examples (see also Biezma \& Rawlins 2017):

(7) (Scenario: John does something really stupid.)

Is John an idiot or is he an idiot?

$\rightsquigarrow$ John is an idiot.

a. You are right.

b. \# That's not true!

(8) wait, harry forgot his passport yesterday? i'm sorry but is he an idiot or is he an idiot? (via Google)

(9) am i a Nerd? or am i a Nerd? I have been been spending my Holiday Vacation in front of the PC. (sic; via Google)

Intuitively, a doubled alternative question offers the hearer a choice between its presented alternatives with no other options, but because the alternatives are 
identical, presents no choice at all. Following Biezma \& Rawlins 2012, 2017 we take the rhetorical signal of doubled alternative questions to follow directly from their semantics and conventionally encoded presuppositions. In the case of doubled AlTQs, any Hamblin-style account of disjunction (Simons 2005; Alonso-Ovalle 2005,2006 ) that treats 'or' as a set union operation makes a clear prediction (at least without further machinery): identical denotations will lead to a singleton set denotation for the question.

(10) Is John an idiot or is he an idiot?

$$
\llbracket(\mathbf{1 0}) \rrbracket=\left\{\lambda w_{s} . \mathbf{J} . \text { is an idiot }\right\} \cup\left\{\lambda w_{s} . \mathrm{J} . \text { is an idiot }\right\}=\left\{\lambda w_{s} . \mathrm{J} . \text { is an idiot }\right\}
$$

The second piece of the story comes from the account of the ALTQ final falling contour found in AltQs in Biezma 2009; Biezma \& Rawlins 2012 (see also Bartels 1999). On this proposal, the falling contour corresponds to a Zimmermann 2000-inspired 'closure operator' that scopes over the question; this operator indicates that the alternatives picked out by the question are exhaustive (see Pruitt \& Roelofsen 2013 for a discussion of alternatives). Biezma \& Rawlins suggest in particular that the final fall indicates that the alternatives exhaust the salient Question Under Discussion (QUD), and that the QUD must itself exhaust the set of discourse possibilities. If there is only one alternative that is part of the question meaning, then the prediction is that the question presupposes that that single alternative itself exhausts the space of possibilities. For present purposes we will simplify this, taking ALTQs to simply presuppose exhaustivity directly (Belnap \& Steel 1976; Karttunen \& Peters 1976; Higginbotham 1991). The meaning of the doubled ALTQ in (10) following Biezma \& Rawlins 2012 is as in (12):

$$
\llbracket(\mathbf{1 0}) \rrbracket^{c}=\left\{\lambda w_{s} . \mathbf{J} . \text { is an idiot }\right\} \cup\left\{\lambda w_{s} . \mathrm{J} . \text { is an idiot }\right\}=\left\{\lambda w_{s} . \mathrm{J} . \text { is an idiot }\right\}
$$
defined only if $\forall w \in c: \exists p \in \llbracket(\mathbf{1 0}) \rrbracket: p(w)$

Without a dynamics for questions, it is not necessarily easy to see what to make of such a question, but intuitively, doubled-alternative questions on the Biezma \& Rawlins 2012 analysis of alternative questions are predicted to fall into the category of rhetorical questions: they signal that their answer is entailed in the context of utterance since they presuppose that the answer must be the redundant content proposition. Hence, doubled alternative questions present just another strategy to signal that the question presupposes the answer and hence that the question has a rhetorical reading.

In terms of Guerzoni 2003, which reduces question bias (where question bias is taken to be any non-inquisitive inference that can be drawn from a question) to the presuppositions of questions, alternative questions on the Biezma \& Rawlins view always signal some bias, due to the presupposition from the closure operator. 
Rhetorical questions: Severing questioning from asking

Doubled ALTQs are simply the limiting case of that, where the 'bias' (in this sense) leads to a completely rhetorical reading (i.e. a reading that does not depend on the context of utterance and doesn't leave any room for alternative answers). In purely semantic terms, we can define a notion of informativity as in (13) (Biezma \& Rawlins 2017); an alternative set is purely informative relative to a context just in case the result of intersecting every alternative in the set with the context leads to a singleton alternative set, i.e. the context resolves the question (see e.g. Roberts 1996; Groenendijk 1999 for similar definitions). This is slightly more general than we need; it follows directly that any singleton alternative set whose content proposition is compatible with a context, is purely informative relative to that context.

\section{(13) (Pure) informativity}

A set of propositions $A$ is purely informative relative to a context set $c$ iff $\left|\left\{p \in D_{\langle s t\rangle} \mid p \neq \emptyset \wedge \exists q \in A: p=q \cap c\right\}\right|=1$

In sum, in a doubled alternative question the speaker commits to the belief that the (unique) content proposition is true in the context, by presupposing it. This is grammatically conveyed: it is derived from the properties of alternative questions, namely from the fact that alternative questions exhaustify logical space. This linguistic presupposition triggers a pragmatic presupposition, which if accommodated, will mean that it is common ground that the content proposition is true - once again, the classic setup of a rhetorical question.

The German particle Schon In doubled alternative questions, the rhetorical effect is a byproduct of many interacting factors. Some languages, such as German, also make use of particles like schon that can directly signal that the utterance of an interrogative is meant to be interpreted as a rhetorical question (see Meibauer 1986 and much following work):

(14) A: Du hättest Hans helfen müssen. you had Hans help must

'You should have helped Hans.'

B: Was hätte ich tun können?

what had I do can

'What could I have done?' (Interpretation as RhQ Depends on prosody)

B': Was hätte ich schon tun können?

what had I SCHON do can

'What could I have done?'

(RhQ only) 
The interpretation of the utterance of the interrogative sentence in the absence of schon can be that of a rhetorical question if it has a specific prosody, but the presence of schon forces it to be rhetorical. A widely accepted view on discourse particles take them to relate the utterance content to the context (see Zimmermann 2011 for an overview) and hence it is not surprising that there is a particle like schon whose presence turns an information seeking question into a rhetorical question.

\subsection{The context of utterance in combination with the signal}

If RhQs presuppose that the context of utterance entails the answer, they should be infelicitous in situations in which the presupposition does not pan out, as well as in situations in which the inferrable answer is controversial in the common ground. Let us take the examples below:

a. John thinks that it would be fun just to pour a gallon of water over Tim's head (who is unaware of John's actions concentrated on studying for his next exam) and he goes ahead and does just that:

T: Are you an idiot?

(with rhetorical prosody)

b. John is about to jump from the top of a tree:

T: Is that guy crazy?

(with rhetorical prosody)

Tim's utterances in (15) would be infelicitous in scenarios in which John does not do anything construable as "crazy/idiotic behavior". However, once the context of utterance can be construed as entailing the answer to the question, the question as a RhQ is felicitous. However, Imagine that the addressee in (15b) knows that John is indeed a stunt-man practicing for his next gig. Upon Tim's utterance the addressee understands that Tim is taking the facts in the context of utterance (available to everybody) to entail an (incorrect) answer. At this point it may be clarified that the contextual cues can be understood differently once Tim has the extra-information that John is a stunt-man. Tim's utterance was felicitous, but his understanding of the context was (understandably) not accurate. In (15a), upon Tim's utterance John realizes that Tim is conveying that the answer to the question is obvious/entailed in the context of utterance (and the obvious answer to Tim is that John is an idiot). John may realize at that point that maybe he went too far with his joke, and attempt to explain that he is not really an idiot but just wanted to do something funny.

In both of these cases, if the addressee responds with something other than acceptance, they are effectively setting aside their interlocutor's (speaker) presuppositions as incorrect. What is important for us is that the presupposition that the context entails the answer can be accommodated from a linguistic presupposition trigger (Guerzoni 2003) (prosody in the cases above). Here is another example: 
Rhetorical questions: Severing questioning from asking

(16) A: I don't understand why John voted for Susan.

B: Who do you think hired him? (with rhetorical prosody)

A: Ah! That makes sense.

As in (15), the speaker can use prosody to signal that the answer is entailed in the context of utterance (and, hence, that it is part of the common ground). There are however other means of signalling rhetoricity, like the use of strong NPIs or minimizers (Borkin 1971), such as "lift a finger" as in Who lifted a finger to help Luca?, which triggers the inference, in this case, that it is impossible to find a person with the property of having helped Luca. Intuitively, the inference is the result of the speaker willing to go as far as enlarging the domain of quantification to include people who merely lifted a finger and make it count as "helping". Notice that rhetoricity is not conventionalized in the semantics of the NPIs above. For example, it is worth noting that not in all contexts of utterance in which the interrogative includes such NPIs the interrogative is interpreted as a rhetorical question. Imagine John's car breaks down when passing by a town he is not familiar with, his uttering of where on earth do I find a mechanic in this town? is not a rhetorical question necessarily. It is interpreted as John's indication of the difficulty of finding a mechanic in a town unknown to him. In addition, we can achieve similar interpretations in the absence of NPIs but with elements that convey "extremes" in similar ways in the right context of utterance such as $(2 \mathrm{~d}){ }^{8}{ }^{8}$

In summary, an account of rhetorical questions needs to handle two factors: the contribution of a conventional signal to the rhetorical reading, and the interpretation of the question in context. We have seen that the nature of the signal varies quite widely, from presupposition triggers that strongly enforce a rhetorical reading, to prosodic cues that are fairly hard to pin down. We turn now to giving a formal account that has room for handling all of these cases: in our specific proposal we focus more on cases where there is a direct signal of rhetoricity.

\section{A minimal dynamics for severing asking \& questioning}

In this section we implement a minimal, Stalnakerian (Stalnaker 1978, 2002) dynamics inspired by Farkas \& Bruce 2010 that separates out 'asking' a question which proposes to update the context, from the 'questioning' step - which involves

8 This example is based on an actual utterance Harry Potter: The Chamber of Secrets (41'40" in the movie) where Harry is serving detention with self-centered celebrity professor Gilderoy Lockhart:

(i) GL: Can you possibly imagine a better way to serve detention than by helping me to answer my fan-mail? 
actually changing what question is currently under discussion in the discourse. The dynamics is Stalnakerian in that it involves a context representing public, mutual information in discourse that agents are coordinating on. To implement the idea that speech acts introduce proposals, we use an idea from Gunlogson 2001; Farkas \& Bruce 2010; Malamud \& Stephenson 2015 among others, that when making a proposal, speakers 'project' potential future discourse states for agents to consider as possibilities; acceptance will involve moving to one of these discourse states. We differ from Farkas \& Bruce 2010 in that this is the only representation of future discourse states (we will not directly have a 'Table' here).

We define the dynamics in two steps. First come what we will term 'local updates' - the updates that directly change a context. We then lift these updates into proposed updates. A local context consists of a context set and QUD, which we implement using a simple alternative-semantics representation.

A local context is a tuple $\langle c s, Q\rangle$ such that:

a. $c s$ is a context set.

b. $Q$ is a stack of sets of propositions.

For the empty stack we will write \langle\rangle , and we will assume the usual stack operations (push, pop, top; see e.g. Kaufmann 2000 for their introduction in linguistics). The current $Q U D$ in a local context $l$, if there is one, is always the top of the stack, top $\left(Q_{c}\right)$. Updates to local contexts will be relatively straightforward: asserting will intersectively reduce the context set, and questioning will put a new question on the QUD stack. We require also that both questions and assertions be relevant to the prior QUD, if there is one.

Local updates. For a local context $l$,

a. $l \oplus\left\ulcorner\varphi_{\langle s, t\rangle}\right\urcorner=\left\langle c s_{l} \cap \llbracket \varphi \rrbracket, Q_{l}\right\rangle$

i. $c s_{l}$ is compatible with $\llbracket \varphi \rrbracket$.

(assertability)

ii. $\llbracket \varphi \rrbracket$ is relevant to $\operatorname{top}\left(Q_{l}\right)$

b. $l \oslash\left\ulcorner\varphi_{\{\langle s, t\rangle\}}\right\urcorner=\left\langle c s_{l}, \operatorname{push}\left(Q_{l}, \llbracket \varphi \rrbracket\right)\right\rangle$

i. $c s_{l}$ is compatible with $\{w \mid \exists p \in(\llbracket \varphi \rrbracket): p(w)\}$. (answerability)

ii. $\llbracket \varphi \rrbracket$ is relevant to top $\left(Q_{l}\right)$ or $Q_{l}=\langle\rangle$

We assume that $\varphi$ can carry presuppositions, and if it does, that they must be accommodated using informative update before performing local updates. We will be non-specific about what theory of presupposition we assume, as any treatment compatible with intersective update would work. 
Rhetorical questions: Severing questioning from asking

(19) Accommodation. If $\varphi$ presupposes $\psi$ and $\psi$ is not satisfied in $l$, first update $l$ so that $\psi$ is satisfied.

Schematically: if $\varphi$ with local update operation '@’ presupposes $\psi$, then the full local update with accommodation will be $l \oplus \psi \odot \varphi$.

Projected contexts have the same structure as local contexts. A full context therefore consists of a local context (the current one), and potentially a projected context. While one may want to generalize this for other purposes, in the context of this paper there will be only one or zero projected contexts, and when there are zero, we will notate this slot as $\emptyset$. If there is a projected context, the projected context represents a proposal to update the current context in a certain way, which could be accepted or rejected. The context in this slot corresponds to the Table in the Farkas \& Bruce 2010 system.

(20) A context $c$ is a tuple $\langle c s, Q, \mathscr{F}\rangle$ where its elements are characterized as:

a. $l_{c}=\langle c s, Q\rangle$ is a local context.

b. $\mathscr{F}_{c}$ is either a local context or $\emptyset$. Call $\mathscr{F}_{c}$ the projected context.

Updates on full contexts in this minimal system involve simply projecting new contexts where the appropriate local update has been performed; acceptance of a move involves taking a projected future context and making it actual. We leave open the question of whether one should incorporate any further norms of asserting/questioning into operators like this (e.g. a belief condition).

$$
c+\ulcorner\operatorname{Assert}(\varphi)\urcorner=\left\langle c s_{c}, Q_{c}, l_{c} \oplus\ulcorner\varphi\urcorner\right\rangle
$$

Assertion Constraints:
a. $\mathscr{F}_{c}=\emptyset$
b. $l_{c} \oplus\ulcorner\varphi\urcorner$ is felicitous

$c+\ulcorner$ Question $(\varphi)\urcorner=\left\langle c s_{c}, Q_{c}, l_{c} \oslash\ulcorner\varphi\urcorner\right\rangle$

\section{Questioning}

Constraints:
a. $\mathscr{F}_{c}=\emptyset$
b. $l_{c} \oslash\ulcorner\varphi\urcorner$ is felicitous

$c+\left\ulcorner\operatorname{Accept}_{x}\right\urcorner=\left\langle c s_{\mathscr{F}_{c}}, Q_{\mathscr{F}_{c}}, \emptyset\right\rangle$

Acceptance

To complete the discourse model, we introduce two more 'maintenance' moves: rejecting a proposed future context involves clearing out the projected future, and clearing a QUD involves popping that QUD from the stack. We assume that when QUDs are or become non-inquisitive, they are cleared automatically. (This dynamics for clearing QUDs is adapted most directly from Groenendijk 1999, where this happens automatically as a structural property of how questions are represented in context there.) 
Biezma \& Rawlins

$c+\ulcorner$ Clear $\urcorner=\left\langle c s_{c}, Q_{c}, \emptyset\right\rangle$

Rejection

$c+\ulcorner\operatorname{Pop}\urcorner=\left\langle c s_{c}, \operatorname{pop}\left(Q_{c}\right), \mathscr{F}_{c}\right\rangle$

QUD resolution

a. $\mathscr{F}_{c}=\emptyset$

b. $Q_{c} \neq\langle\rangle$

(26) A local context $l$ is non-inquisitive just in case top $\left(Q_{l}\right)$ is purely informative relative to $c s_{l}$.

(27) Resolved QUDs vanish: Assume that if in $c$ top $\left(Q_{c}\right)$ is completely resolved by $c s_{c}$, i.e. is non-inquisitive in that context, then the context is automatically shifted to $c+\ulcorner$ Pop?

We are now in a position to state a $\mathrm{C} \& \mathrm{~S}$-inspired sufficient condition on rhetoricity in precise terms, as well as characterize the dynamics of rhetorical questions. First, a question is asked, which introduces a proposed future QUD. This question is one that leads to a non-inquisitive QUD, if accepted; the non-inquisitiveness is typically triggered by accommodating a linguistic presupposition and/or adopting a speaker presupposition as common ground. Because the QUD will already be resolved, unlike in the case of ordinary questions there would be no inquisitive impact of accepting the question, and therefore, it will not need an answer. However, by default the accepter will be publicly committed to a context where the resolution of the question is entailed, if they accept the rhetorical question. The Interrogative Form Puzzle is resolved by decomposing the rhetorical move into two steps: even though the second step is trivial, the first step of proposing an update is not trivial.

(28) Sufficient condition for rhetoricity

A question $\mathrm{Q}$ can be rhetorical in $c$ if $\mathscr{F} c+\ulcorner\mathrm{Q}\urcorner$ is non-inquisitive.

Our third hallmark is that rhetorical questions can be answered. We take answerhood licensing in this system to be generally controlled by the licensing dynamics from Roberts 1996, stated below:

(29) Answerhood licensing: an assertion move is relevant to $\mathrm{QUD}_{c}$ only if it entails, either positively or negatively, the resolution of at least one alternative in $\operatorname{top}\left(\mathrm{QUD}_{c}\right)$.

(after Roberts 1996)

The default move in response to a question in general is acceptance, so if it is clear that the sufficient condition is met, very little marking of that acceptance is required. However, in some cases, a speaker may be able to choose not to adopt a speaker presupposition from the author of the rhetorical question. (We do not typically find this with linguistic presupposition triggers, such as the case of doubled alternative questions.) In this case, the responder simply takes the question to be 
genuine and the resulting context to be inquisitive, and responds to it after acceptance as they would any question. Of course, since it was likely public that the questioner intended the question to be rhetorical, the responder is aware of the questioner's beliefs and won't ignore them entirely.

We briefly sketch how this works with doubled alternative questions, assuming they have the semantics sketched in 3.1, where the basic idea is that they reduce to singleton alternative sets because of the semantics of 'or', and presuppose exhaustivity. Suppose that the exhaustivity presupposition projects to the context set of a local context. The local update for a doubled alternative question, where $\varphi$ is the content proposition, therefore amounts to:

$$
\begin{aligned}
& l \oslash\ulcorner[\varphi \text { or } \varphi]\urcorner=l \oslash\{\ulcorner\varphi\urcorner,\ulcorner\varphi\urcorner\} \\
& \text { presupposition: } \forall w \in c s_{l}: \exists p \in\{\ulcorner\varphi\urcorner,\ulcorner\varphi\urcorner\}: p(w)
\end{aligned}
$$

Clearly, doubled alternative questions, with accommodation, will meet the sufficient condition for rhetoricity - it follows from this presupposition that a local context updated with a doubled alternative question must be non-inquisitive. This proposal also allows for a very straightforward sufficient-condition treatment of 'schon' whereby it directly indicates non-inquisitive realtive to a local update. We leave detailed exploration of the details of this idea, as well as comparison to previous literature, for future work:

$$
\begin{aligned}
& l \oslash\ulcorner\operatorname{schon}(\varphi)\urcorner=l \oslash\ulcorner\varphi\urcorner \\
& \text { presupposition: } l \oslash\ulcorner\varphi\urcorner \text { is non-inquisitive. }
\end{aligned}
$$

A speaker hearing a 'schon' question must infer what their interlocutor has in mind for the context such that the result of updating with the question is non-inquisitive. Where the doubled alternative question provides this directly, on this proposal a 'schon'-marked question doesn't necessarily provide any information about the answer in its semantics, but would only be felicitous if the answer is inferrable.

Finally, we briefly return to the two commitment-related effects of rhetorical questions. We observed earlier in the paper that RhQs often are used to extract public commitments from the hearer, and that they are infelicitous if there is a public commitment to the rhetorical point (the commitment constraint). In the present account, both of these effects can follow from general principles about commitment. While for space reasons this formal system does not directly implement a notion of commitment, adding one in the style of Farkas \& Bruce 2010 or Malamud \& Stephenson 2015 would be straightforward. Informally, we take speakers to indicate public commitment to the content of assertions they propose or accept into the common ground, and we also take speakers to be committed to anything they presuppose or accept as a presupposition - and by indicating a presupposition, to make this commitment public. Therefore, by accepting a rhetorical question, a responder signals 
commitment to the presupposition(s) that make it rhetorical, regardless of whether they provide an explicit answer that aligns to this presupposition. A responder can, as is normal, reject the presupposition as well, leading to an inquisitive context in which they would most naturally answer. We also suggest that the commitment constraint derives from general principles. We take a question (in general) to be infelicitous if another agent in the discourse has already publicly committed to an answer, and so the commitment constraint follows.

Differences between assertions and questions On this proposal, the effect of a two-step assertion update (proposal + acceptance) is the same as that of a comparable rhetorical question two-step update. The 'content' of the utterance is now public / common ground, and both speakers are committed to that content. However, by decomposing into these two steps, we can see that the path to achieve this result is very different. The proposal stage for each move is entirely different, and rhetorical 'contents' are not contents at all (contra e.g. Reese 2007), but rather the product of potentially complicated interactions of presuppositions and context at the acceptance stage. One prediction this makes is that rhetorical 'contents' should be less accessible for future propositional anaphora, something that can be seen from the response patterns to rhetorical questions vs. assertions.

(32) A: You should stop saying that Luca didn't like the party last night. After all, who was the only one that was still dancing at 3am?

B: Luca. You are right. $\quad$ (adapted from Caponigro \& Sprouse 2007)

A response like "you are right" is acceptable, but this does not indicate that the question move is the same as a comparable assertion. To a comparable assertion a hearer could always respond with "that is true" or "that is false", but these more strictly anaphoric responses are not possible as a response to a RhQ as in (33). Where intent can be discerned, it is always licit to agree or disagree with the intent, as in (32), but pronouns such as 'that' that make reference to propositional content are not typuically licensed following rhetorical questions. Further, rhetorical disagreements are often marked as targeting not-at-issue content, e.g. by 'actually'.

(33) A: Such a silly idea! Who on earth will buy a book on rhetorical questions?

B: \# That is not true!

B': Actually, I would.

Summing up, the act of asking an information-seeking question signals that there are multiple discourse paths towards resolving the question that the speaker can't or won't decide between; it further requests that addressee(s) address the question. A 
Rhetorical questions: Severing questioning from asking

rhetorical question does not signal the first part: the speaker knows the answer, and because of the iterative nature of Stalnakerian pragmatics, they believe the addressee can know the answer. However, the addressee-oriented effect still applies. The addressee should address the proposal to update the QUD, and by accepting such a proposal, they would indicate that they too commit to the answer.

\section{Conclusion}

Severing asking from questioning in the dynamics of interrogative utterances allows us to resolve the tension between the form and the effect of RhQs, and gain traction on the Interrogative Form Puzzle. RhQs are interrogatives that signal the speaker's attitude towards the answer, in particular, that the answer is entailed in the context of utterance and, therefore, that all discourse participants are privileged to it. The final update of a RhQ is then similar to the update that would be driven by its assertion counterpart, but the route towards this result is quite different. Rhetorical questions propose to update the QUD with a question that would be trivially non-inquisitive, forcing accommodation of this non-inquisitivity in the context set, whereas assertions propose to update the context set directly.

Our account of the IFP rests on the differences between the two types of moves at the proposal stage. Where assertions are characteristically used to introduce a new commitment, RhQs are very well-suited for extracting commitments, especially when an agent believes a commitment should have already been given, and hence speakers may prefer to utter the loaded interrogative form instead of the declarative counterpart. The ultimate effect of the dynamic update may end up being the same, but assertions and questions leave different amounts of room for maneuvering at the proposal stage, and this is something speakers can exploit in discourse.

This treatment takes a stand on the question of what participants can accommodate, requiring a wide range of speaker presuppositions to be amenable to accommodation (Stalnaker 2014): RhQs can draw attention to entailments of information taken to be already in the CG by a speaker, and take the CG-status of this entailed information for granted. On our proposal, accommodating a RhQ amounts to either acknowledging such entailments (which may also involve accommodating new dependencies between facts, cf. Veltman 2005) or even accommodating information that would lead to the acceptance of such entailments by some agent. At any rate, our proposal assumes that interlocutors can rightfully assume that what it is to be CG is closed under entailment, at least when signaled. However, closure without signalling is much too strong (see Yablo 2014 among many others). We leave further exploration of the limits of the interaction of this closure property and rhetorical questions for future investigation. 
Biezma \& Rawlins

\section{References}

Alonso-Ovalle, Luis. 2005. Distributing the disjuncts over the modal space. In Leah Bateman \& Cherlon Ussery (eds.), North East Linguistic Society 35, UMass, Amherst: GLSA.

Alonso-Ovalle, Luis. 2006. Disjunction in alternative semantics. Amherst, Massachusetts: University of Massachusetts at Amherst Ph.D. dissertation.

Banuazizi, A. \& C. Creswell. 1999. Is that a real question? Final rises, final falls, and discourse function in yes-no question intonation. In Papers from the $35^{\text {th }}$ Regional Meeting of the Chicago Linguistic Society 35, 1-14.

Bartels, Christine. 1999. The Intonation of English Statements and Questions. Garland Publishers.

Belnap, Nuel \& Thomas Steel. 1976. The Logic of Questions and Answers. Yale University Press.

Biezma, María. 2009. Alternative vs. polar questions: The cornering effect. In Ed Cormany, Satoshi Ito \& David Lutz (eds.), Semantics and Linguistic Theory $19,37-54$.

Biezma, María \& Kyle Rawlins. 2012. Responding to alternative and polar questions. Linguistics and Philosophy 35. 261-406.

Biezma, Maria \& Kyle Rawlins. 2015. Alternative questions. Language and Linguistics Compass 9(11). 450 - 468.

Biezma, María \& Kyle Rawlins. 2017. Or what? To appear in Semantics and Pragmatics.

Borkin, Ann. 1971. Polarity items in questions. In CLS 7, 53-63.

Caponigro, Ivano \& Jon Sprouse. 2007. Rhetorical questions as questions. In Estela Puig-Waldmueller (ed.), Sinn und Bedeutung 11, 121-133.

Cutler, Anne. 1977. The context-dependence of 'intonational meanings'. In Papers from the Thirteenth Regional Meeting, Chicago Linguistic Society 13, 104-115.

Farkas, Donka \& Kim Bruce. 2010. On reacting to assertions and polar questions. Journal of Semantics 27. 81-118.

Ginzburg, Jonathan. 2012. The Interactive Stance: meaning for conversation. Oxford University Press.

Ginzburg, Jonathan \& Ivan Sag. 2001. Interrogative investigations. Stanford, CA: CSLI Publications.

Groenendijk, Jeroen. 1999. The logic of interrogation. In Tanya Matthews \& Devon Strolovitch (eds.), Semantics and Linguistic Theory 9, 109-126. Ithaca, NY: CLC Publications.

Groenendijk, Jeroen \& Martin Stokhof. 1984. Studies in the semantics of questions and the pragmatics of answers. Amsterdam: University of Amsterdam Ph.D. dissertation. 
Rhetorical questions: Severing questioning from asking

Guerzoni, Elena. 2003. Why Even ask? Cambridge, Massachusetts: Massachusetts Institute of Technology Ph.D. dissertation.

Gunlogson, Christine. 2001. True to Form: Rising and Falling Declaratives as Questions in English. New York, London: Rutledge.

Gutiérrez Rexach, Javier. 1997. The semantic basis of NPI licensing in questions. In B. Bruening (ed.), SCIL 31 MIT Working Papers in Linguistics, 359-376. Cambridge, MA: Massachusetts Institute of Technology.

Han, Chung-hye. 2002. Interpreting interrogatives as rhetorical questions. Lingua 112(3). $201-229$.

Han, Chung-hye \& Laura Siegel. 1996. Syntactic and semantic conditions of npi licensing in questions. In West Coast Conference on Formal Linguistics 15, Stanford: CSLI Publications.

Heeren, Willemijn F.L., Sarah A. Bibyk, Christine Gunlogson \& Michael K. Tanenhaus. 2015. Asking or telling: Real-time processing of prosodically distinguished questions and statements. Language and Speech 58(4). 1-28.

Higginbotham, James. 1991. Either/or. In North East Linguistics Society 21, 143155.

Hintikka, Jaakko. 1962. Knowledge and belief. Cornell University Press.

Karttunen, Lauri \& Stanley Peters. 1976. What indirect questions conventionally implicate. In CLS 12, .

Kaufmann, Stefan. 2000. Dynamic context management. In Martina Faller, Stefan Kaufmann \& Marc Pauly (eds.), Formalizing the Dynamics of Information, Stanford, CA: CSLI.

Ladusaw, William A. 1979. Polarity sensitivity as inherent scope relations. Austin, Texas: UT Austin Ph.D. dissertation.

Malamud, Sophia \& Tamina Stephenson. 2015. Three ways to avoid commitments: declarative force modifiers in the conversational scoreboard. Journal of Semantics 32. 275-311.

Meibauer, Jörg. 1986. Rhetorische Fragen. Linguistische Arbeiten 167. Tübingen: Max Niemeyer Verlag.

Neitsch, Jana, Marianne Kusterer, Nicole Dehé \& Bettina Braun. 2017. The role of prosody for the interpretation of rhetorical questions in German. Ms. University of Konstanz.

Progovac, Ljljana. 1993. Negative polarity: Entailment and binding. Linguistics \& Philosophy 16. 149-180.

Pruitt, Kathryn \& Floris Roelofsen. 2013. The interpretation of prosody in disjunctive questions. Linguistic Inquiry 44. 632-650.

Reese, Brian. 2007. Bias in questions. Austin, Texas: UT Austin Ph.D. dissertation.

Roberts, Craige. 1996. Information structure in discourse: Towards an integrated formal theory of pragmatics. In Jae Hak Yoon \& Andreas Kathol (eds.), OSUWPL 
Biezma \& Rawlins

vol. 49: Papers in Semantics, The Ohio State University.

Rohde, Hannah. 2006. Rhetorical questions and redundant interrogatives. San Diego Linguistics Papers 2. 134-168.

van Rooy, Robert. 2003. Negative polarity items in questions: Strength as relevance. Journal of Semantics 20. 239-273.

Sadock, J. 1971. Queclaratives. In CLS 7, 223-331.

Sadock, J. 1974. Towards a linguistic theory of speech acts. Academic Press.

Sag, Ivan A. \& Mark Liberman. 1975. The intonational disambiguation of indirect speech acts. In Papers from the Eleventh Regional Meeting of the Chicago Linguistics Society, 487-498.

Searle, John R. 1969. Speech Acts. Cambridge University Press.

Simons, Mandy. 2005. Dividing things up: The semantics of or and the modal/or interaction. Natural Language Semantics 13. 271-316.

Stalnaker, Robert. 1970. Pragmatics. Synthese 22(1-2). 272-289.

Stalnaker, Robert. 1978. Assertion. In Peter Cole (ed.), Pragmatics, 315-332. New York: Academic Press.

Stalnaker, Robert. 2002. Common Ground. Linguistics and Philosophy 25. 701-721.

Stalnaker, Robert. 2014. Context. Context and Content. Oxford, UK: Oxford University Press.

Starr, Will. 2016. A preference semantics for imperatives. Manuscript, Cornell.

Veltman, Frank. 2005. Making counterfactual assumptions. Journal of Semantics 22. 159-180.

Wochner, Daniela, Jana Schlegel, Bettina Braun \& Nicole Dehé. 2015. The prosodic marking of rhetorical questions in German. In Interspeech, Dresden, Germany. Yablo, Stephen. 2014. Aboutness. Princeton University Press.

Zimmermann, Malte. 2011. Discourse particles. In Paul Portner, C. Maienborn \& K. von Heusinger (eds.), Semantics: An International Handbook of Natural Language Meaning, 2011-2038. Berlin: Mouton de Gruyter.

Zimmermann, Thomas Ede. 2000. Free choice disjunction and epistemic possibility. Natural Language Semantics 8. 255-290.

María Biezma

Linguistics Department

University of Konstanz,

Universitätstraße 10, PF 185

78454 Konstanz

maria.biezma@uni-konstanz.de
Kyle Rawlins

Cognitive Science Department

Johns Hopkins University

3400 N Charles St, Krieger 237

Baltimore, MD, 21218

kgr@jhu.edu 